\title{
Meaningful Use of an Electronic Per- sonal Health Record (ePHR) among Pediatric Cancer Survivors
}

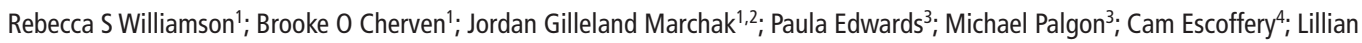
R Meacham ${ }^{1,2} ;$ Ann C Mertens ${ }^{1,2}$

'Aflac Cancer and Blood Disorders Center, Children's Healthcare of Atlanta, Atlanta, GA, USA;

2Department of Pediatrics, Emory University, Atlanta, GA, USA;

${ }^{3}$ HIMformatics, LLC, Atlanta, GA, USA;

${ }^{4}$ Rollins School of Public Health, Emory University, Atlanta, GA, USA

\section{Keywords}

Pediatric cancer survivor, SurvivorLink, electronic personal health record, transition, survivorship

\section{Summary}

Background and Objectivs: Survivors of pediatric and adolescent cancer are at an increased risk of chronic and debilitating health conditions and require life-long specialized care. Stand-alone electronic personal health records (ePHRs) may aid their self-management. This analysis characterizes young adult survivors and parents who meaningfully use an ePHR, Cancer SurvivorLink ${ }^{\top \mathrm{M}}$, designed for survivors of pediatric and adolescent cancer.

Methods: This was a retrospective observational study of patients seen at a pediatric survivor clinic for annual survivor care. Young adult survivors and/or parent proxies for survivors $<18$ years old who completed ePHR registration prior to their appointment or within 90 days were classified as registrants. Registrants who uploaded or downloaded a document and/or shared their record were classified as meaningful users.

Results: Overall, $23.7 \%$ (148/624) of survivors/parents registered and 38\% of registrants used SurvivorLink meaningfully. Young adult registrants who transferred to adult care during the study period were more likely to be meaningful users (aOR: $2.6(95 \% \mathrm{Cl}: 1.1,6.1)$ ) and used the ePHR twice as frequently as those who continued to receive care in our institution's pediatric survivor clinic. Among survivors who continued to receive care at our institution, being a registrant was associated with having an annual follow-up visit (aOR: $2.6(95 \% \mathrm{Cl}: 1.2,5.8)$ ).

Conclusions: While ePHRs may not be utilized by all survivors, SurvivorLink is a resource for a subset and may serve as an important bridge for patients who transfer their care. Using SurvivorLink was also associated with receiving recommended annual survivor care.

Correspondence to:

Rebecca Williamson, MPH

2015 Upper Gate Drive, 4th Floor

Atlanta, GA 30322

Phone: 404.785.9929 Fax: 404.785.9248

Email: rebecca.lewis@choa.org
Appl Clin Inform 2017; 8: 250-264

https://doi.org/10.4338/ACI-2016-11-RA-0189

received: November 4, 2016

accepted: January 8, 2017

published: March 15, 2017

Citation: Williamson RS, Cherven BO, Marchak JG,

Edwards P, Palgon M, Escoffery C, Meacham LR,

Mertens AC. Meaningful use of an electronic personal health record (ePHR) among pediatric cancer survivors. Appl Clin Inform 2017; 8: 250-264

https://doi.org/10.4338/ACI-2016-11-RA-0189

Funding

This work was supported by grants from AHRQ (R18

HS017831) and CURE Childhood Cancer. 


\section{Background}

The overall 5-year survival rate for children diagnosed with cancer is currently more than $80 \%$, with nearly 400,000 survivors of childhood/adolescent cancers currently living in the United States [1, 2]. However, many survivors of childhood cancer are at increased risk for chronic and debilitating late effects such as congestive heart failure, renal failure, and ovarian failure, and recent estimates suggest that by age 45 nearly all survivors will have a chronic health condition [3,4]. Due to increased risk of late effects, pediatric cancer survivors require specialized care and surveillance which are managed by a team of providers and sub-specialists that is unique to each patient. Screening for late effects should be life-long and is recommended to begin at two years after the completion of treatment [5]. Electronic personal health records (ePHRs) may be a way for survivors to improve self-management of their complex medical needs. The core function of an ePHR is to serve as an electronic repository of lifelong health-related information which may be amassed from multiple sources including the patient, their physicians, and other healthcare providers [6-9]. In structured interviews with pediatric cancer survivors and parents of survivors, researchers have found a high interest in the use of ePHRs to assist in managing their complex health information [10].

Currently, there is very limited research on the use of ePHRs in pediatric populations. A retrospective analysis from 2007-2011 at a large integrated managed care organization found that 35.5\% of parents used at least one function of their patient portal, an ePHR tethered to their electronic medical records system [11]. Among those who used the patient portal, there was better adherence to well-child care visit recommendations and significantly more outpatient clinic visits and telephone encounters $[11,12]$. In a separate analysis at a freestanding children's hospital, $27.9 \%$ of families of children with chronic diseases completed their portal registration from 2003-2008 [13]. Pediatric patients with more outpatient visits were more likely to be registered users and to have sustained use of the portal 3-6 months following registration [13]. Taken together, these data indicate that there is a significant subset of parents who are interested in using personal health technology to help manage their children's health and healthcare needs may influence registration and utilization patterns. For survivors of childhood cancer, survivor healthcare plans (SHPs) are recommended to supply new care providers with a concise summary of patients' complex cancer treatment, risks for late effects, and surveillance tests and schedule. Thus, use of ePHRs could play a critical role in the continuation and coordination of evidenced-based survivor healthcare across the lifespan; however, more research is needed to describe how parents and young adult patients use patient-controlled ePHRs untethered to a specific electronic medical records system to manage their care across institutions.

Cancer SurvivorLink ${ }^{\mathrm{TM}}$ (www.cancersurvivorlink.org) is a patient-controlled untethered ePHR designed for survivors of pediatric cancers ( $>$ Figure 1). SurvivorLink allows registered users to upload and store important health documents and electronically share these documents with their providers, regardless of where the providers practice and independent of institutional or practicespecific electronic medical records systems. The ePHR of SurvivorLink is currently a documentoriented repository of health information, allowing users to upload key documents specifically related to their survivor healthcare including their SHP, letters from oncologist or other specialist, hospital discharge notes, etc. Registrants can upload any file $<5 \mathrm{MB}$, including Microsoft Word, PDF, scanned image, or text files. The documents are encrypted and stored in the database. SurvivorLink also offers survivor-focused educational material for survivors and their caregivers as well as free continuing medical education for providers. During initial recruitment of pediatric cancer survivors to use SurvivorLink, we found that survivors who had been seen in a cancer survivor clinic were the most likely to register and use SurvivorLink as compared to survivors who had never been seen in a survivor clinic [14]. The objective of this analysis was to characterize how young adult survivors and parent proxies of survivors $<18$ years old seen in a pediatric survivor clinic use SurvivorLink and if the use of this ePHR was associated with increased recommended annual survivor care. 


\section{Methods}

This was a retrospective observational study of all English-speaking pediatric cancer survivors $\leq 21$ years old seen in the multi-disciplinary Aflac Cancer Survivor Clinic at Children's Healthcare of Atlanta during an 18-month period in 2012 and 2013. Since patients must be 2 years since the completion of cancer therapy, no survivors $<2$ years old were included in this analysis. Among patients seen during this period, follow-up survivor clinic visits and SurvivorLink usage data were collected through December 31, 2014. During their survivor visit, all patients received an individualized survivor healthcare plan (SHP) summarizing their cancer history and treatment, the late effects they are at risk for and the corresponding surveillance plan based on national recommendations by the Children's Oncology Group Long-Term Follow-up Guidelines (COG-LTFU) [5]. Patients underwent recommended screening labs and diagnostic tests during their visit as directed by their SHP. Patients diagnosed with a brain tumor were excluded from this analysis as they are seen in a separate multi-disciplinary clinic. This study was reviewed and approved by the Children's Healthcare of Atlanta Institutional Review Board.

All patients seen during the study period received printed material describing SurvivorLink in their mailed pre-clinic packet. Providers and nursing staff in the cancer survivor clinic are familiar with SurvivorLink and offer it as a resource to all survivor patients. The process to register and create a personal health record has previously been described [14]. Briefly, survivors $\geq 18$ years old and parent proxy of survivors $<18$ years old register using an active email address. To ensure protection of personal health information, registration is completed once the user verifies their account using a link sent to the email address. After completing registration, users must log-in and create their or their child's personal health record using a step-by-step wizard. During the creation of their health record, users may select the clinic where they receive their survivor care. If a young adult survivor $\geq 18$ years old or parent proxy of patients $<18$ years old completed a medical records release for SurvivorLink, clinic staff are able to upload the SHP to the survivor's personal health record. SurvivorLink was developed with grant funding and is completely free to all users.

Information regarding survivors' demographic, diagnosis, treatment, and insurance status at their clinic visit was abstracted from the patient's medical chart by one author (RW). Treatment was summarized in a general hierarchy of risk for late effects: highest risk were survivors who had a bone marrow transplant, moderate risk were those who received any radiation, and lowest risk were those who received chemotherapy or surgery only. Treatment groups were mutually exclusive with survivors being assigned to their highest risk group. Further, dates of all completed follow-up visits to the survivor clinic through December 31, 2014 were abstracted. At Children's Healthcare of Atlanta, an independent pediatric hospital system, patients are unable to be seen after the age of 21 . Documentation of being transitioned to an adult survivor clinic or primary care physician during the study period was abstracted. Additionally, pediatric patients who transitioned their care to an out of state survivor clinic also were identified.

Young adult survivors or parents proxies who completed SurvivorLink registration prior to their appointment or within 90 days of their appointment were classified as SurvivorLink registrants. A window of 90 days for registration was used to ensure survivors had received all clinic documentation and results following their appointment. The list of patients seen at the Aflac Cancer Survivor Clinic along with their parent(s)' or legal guardian(s)' name(s) were linked with the SurvivorLink user list to determine whether the survivor or the parent proxy were registered. For survivors with health records on SurvivorLink, the clinic list was linked by patient name and date of birth. For the remaining survivors, the clinic and user lists were linked by patient first and last name for survivors $\geq 18$ years old and parent or legal guardian's first and last name for survivors $<18$ years old. The SurvivorLink user list was then manually reviewed by one author (RW) for all survivors seen who did not automatically match. Among SurvivorLink registrants, the dates of all document uploads and downloads as well as dates of any sharing invitation were obtained from the SurvivorLink usage data. SurvivorLink registrants who uploaded or downloaded a document from their survivor health record and/or shared their record during the observation period were considered to be "meaningful users." This definition was used to highlight the SurvivorLink functionality that is aligned with Stage 2 of Meaningful Use for Medicare or Medicaid Electronic Health Records Incentive Programs, which has been incorporated as the advancing care information in the Merit-based Incentive Pay- 
ment System (MIPS) of the Medicare Access and CHIP Reauthorization Act of 2015 (MACRA) [15, $16]$.

\subsection{Statistical Analysis}

Descriptive statistics for all survivors seen in clinic were performed. All continuous variables were analyzed as categorical variables; age at diagnosis and survivor visit and time since completion of treatment were categorized in five year increments and age at survivor visit accounted for age of the legal majority. Comparisons of survivor demographic and cancer-related factors between SurvivorLink registrants and those who did not register were made using independent chi-square tests. Among SurvivorLink registrants, comparisons of those who used SurvivorLink meaningfully to those who did not were made using chi-square tests. Logistic regression was used to determine factors associated with using SurvivorLink meaningfully among registrants. To show how often and when registrants used SurvivorLink meaningfully, timelines for each registrant were created documenting when each meaningful event occurred.

To determine if SurvivorLink use was associated with annual survivor care, patients who were eligible to receive their annual survivor care at our clinic $(<21$ years old at follow-up visit with no documentation of transition of care) were identified. The overall return rate was calculated and comparisons of demographic and cancer-related factors between those who returned and those who did not were made using chi-square tests. Logistic regression was used to determine if survivor race/ ethnicity, history of a relapse or second malignancy, age at survivor visit, and the use of SurvivorLink had an association with a patient's return to clinic. All analyses were conducted using SAS version 9.4 (Cary, NC). For all analyses, p-values $<0.05$ were considered to be statistically significant.

\section{Results}

During the observation period, 722 survivors 2-21.9 years old were seen. Survivors who were nonEnglish speaking and required an interpreter $(n=72)$, had relapsed or developed a secondary malignancy $(n=13)$, were deceased at time of analysis $(n=4)$, were less than 1.5 years from the completion of treatment $(n=5)$, or had documented recommended follow-up visit that was outside the study timeframe $(n=4)$ were not included in the analysis. The final dataset included 624 survivors who were $54.3 \%$ male, $69.2 \%$ white, and were 13.8 (SD:4.5) years old at their survivor visit ( $>$ Table 1 ). The most common diagnosis was leukemia (45.0\%). There were 119 survivors with documentation of transition of their annual survivor care during the observation period.

Overall, $23.7 \%$ (148/624) of survivors or parents proxies registered for SurvivorLink prior to their appointment or within 90 days of their appointment ( $>$ Table 1 ). There were 32 young adult survivors and 116 parents proxies who registered. Survivors or parents proxies who are white or Asian were more likely to be a SurvivorLink registrant $(\mathrm{p}=0.01)$. However, there was no association between being a SurvivorLink registrant and cancer diagnosis, type of cancer treatment, type of survivor visit, type of insurance, or if a survivor had transitioned. There were 81 registrants (54.7\%) who completed the medical records release process for clinic to upload their SHP to their health record.

Among SurvivorLink registrants, 38\% (56/148) used SurvivorLink in a meaningful way after their survivor visit including uploading and storing a document to their health record in addition to a document uploaded by clinic, downloading a stored document, and/or sharing their health record with a registered provider. Those who were black were significantly less likely to use SurvivorLink in a meaningful way while young adult registrants or those who transitioned during the observation period were significantly more likely to use SurvivorLink in a meaningful way. Young adult registrants who were $\geq 18$ years old and transitioned during the observation period were 2.6 (95\%CI: 1.1, 6.1) times more likely to use SurvivorLink meaningfully as compared to those $<18$ years old who continued to receive their survivor care in our clinic, when controlling for survivor race/ethnicity.

- Figure 2 shows when each of the registrants who used SurvivorLink meaningfully downloaded or uploaded a document or shared their health record in relation to their survivor clinic visit. Registrants who did not transition from pediatric survivor care $(n=41)$ tended to use SurvivorLink fol- 
lowing a survivor clinic visit with a median number of 2 meaningful events (range: 1-8). Registrants who transitioned $(n=15)$, on the other hand, used SurvivorLink more frequently throughout the timeframe with a median of 4 meaningful events (range: $1-32$ ).

Most importantly, of the 624 survivors included in the analysis, 560 (89.7\%) were eligible to return to our pediatric survivor clinic for their annual survivor care visit. Overall, $88.6 \%(n=496)$ had at least one follow-up visit. When controlling for survivor race/ethnicity, history of relapse or second malignancy, and age at survivor visit, SurvivorLink registrants were more likely to return to our clinic for their annual survivor care (aOR: 2.6 (95\% CI: 1.2, 5.8); Table 2). Among the 136 SurvivorLink registrants, $36.8 \%(\mathrm{n}=50)$ were meaningful users and nearly all meaningful users returned for their annual care (48/50). There was no significant difference in follow-up clinic attendance between meaningful users and those who had only registered for SurvivorLink $(\mathrm{p}=0.46)$. Furthermore, among patients who had not registered at their previous visit, $15.2 \%$ completed registration within 90 days of their follow-up visit.

\section{Discussion}

The use of ePHRs, such as SurvivorLink, has been envisioned as one of the ways to improve patient engagement in healthcare and is called for in the cancer survivor literature [17-20]. This study describes how and when a patient-controlled ePHR is utilized by young adult survivors of childhood cancer and parent proxies of survivors $<18$ years old. The need for such a resource in this vulnerable population is evident as demonstrated by patients who left our pediatric institution, and especially young adults transitioning to adult care, who have used SurvivorLink as a resource for their health information when they were no longer being seen in our clinic. Nationally, Stage 2 of Meaningful Use suggests that $5 \%$ of active patients have the ability to view online, download or transmit their health information [21]. Our clinic nearly doubles the national goal with $9 \%$ (56/624) of all survivors seen in our clinic or parent proxies of survivors $<18$ years old uploading or downloading a document and/or sharing their health record. Recognizing that only a segment of a population will want to use ePHRs, we found nearly $40 \%$ of registrants used SurvivorLink meaningfully with minimal prompting by providers. While the overall uptake of ePHRs has been slow, patients with multiple comorbidities and chronic conditions that require self-management, like pediatric cancer survivors, may be more likely to adopt and benefit from an ePHR compared to other patients [22, 23]. Complex patients who see multiple providers and have more frequent visits are likely to have information management and communication challenges compared to healthier patients. The life-long surveillance for, and treatment of, late effects can be similar to the management of chronic illness. Thus, it is not surprising that we found similar patterns of utilization (24\% registration rate) as compared to pediatric patient portals among parents of children with chronic illnesses (27.9\% registration rate) [13]. Also, our analysis is consistent with results from the literature showing that ethnicity may impact personal health technology utilization $[11,13]$; we found that White, non-Hispanics were more likely to register and use SurvivorLink. More research is needed into the preferences and barriers of using an ePHR in minority populations.

The type of personal health record - a patient portal tethered to an electronic medical records system versus a patient-controlled untethered ePHR - provides different values for patients and providers $[6,24]$. Much of the value of tethered patient portals increases efficiencies for providers, offering patients quicker access to lab results, prescription refills, referrals, and appointment scheduling [ $24,25]$. Patient portals can also be used to communicate with providers about non-urgent medical matters [24]. However, patients who have providers in multiple independent healthcare systems often have separate, non-interoperable portals for each provider, even if the providers are loosely affiliated within the same healthcare system or clinically integrated network [25]. When a patient controls their ePHR, they are able to consolidate health information from multiple sources and have immediate access to their pertinent health information $[24,26]$. If the patient-controlled ePHR is able to be shared with providers regardless of the institution, as with SurvivorLink, providers are able to review personal health information from other providers and can use this information in clinical decision making and potentially reduce duplication of clinical services $[24,26]$. It is important to note that our institution does offer patients access to portions of their electronic medical record (i.e. 
medications, lab results) via a patient portal; the patient portal does not support access to the SHP which summarizes their cancer history, treatment, and recommended surveillance as the SHP is stored in our electronic medical record system as clinical notes which are not currently available via the patient portal. The majority of the meaningful events that occurred in this analysis were registrants downloading the SHP uploaded by the clinic, suggesting access to this document is important to cancer survivors.

This study is the first to our knowledge that characterized how young adult survivors use a personal health record when they are transitioned from pediatric care. In our study population, the small number of young adult survivors with documented transition of care were most likely to use SurvivorLink meaningfully and used it twice as frequently and more consistently as compared to those who continued to receive their survivor care in a pediatric care setting. Since SurvivorLink is independent and untethered to an electronic medical record system, survivors are able to create a longitudinal health record containing important health documents from all of the providers they see in both pediatric and adult care. This addresses common barriers to effective transition to adult care, transition support tools, and sharing of a transition plan among providers [27, 28].

Furthermore, while the proportion of survivors who returned for an annual survivor care visit was nearly $90 \%$ overall, those who were SurvivorLink registrants were significantly more likely to have a follow-up visit. These findings are consistent with the findings from the literature showing that use of patient portals is associated with increased clinic visits [11-13]. While all of these studies, ours included, found an increase in the number of clinic visits and completion of preventative care, it is unclear if use of the personal health record drove the increase or if there is reverse causation and use of a personal health record is simply a proxy for those who are more engaged in their care. However, a recent study reported that patients who experienced an acute myocardial infarction, congestive heart failure, or pneumonia who were active users of their patient portal were $66 \%$ more likely to be re-admitted within 30 days [29]; highlighting those with high morbidity may benefit the most from ePHR use. Additionally, no study has measured markers of health technology literacy and comfort of use and their impact on personal health record utilization and patient engagement. It has been estimated that only half of parents are interested in using personal health records even with substantial effectors to promote their use and provide technical support [30]. Understanding the relationship between health technology literacy and comfort of use and their impact on personal health record utilization and patient engagement will be important to informing future designs that more effectively engage historically underserved populations.

In addition to the fact that observational studies such as this one can only measure associations and not causations, there are other limitations to this analysis. This analysis was limited to Englishspeaking families because even though SurvivorLink has Spanish educational material available, the contents of the website itself are currently only available in English. It is unknown how the use of ePHRs may decrease language barriers and should be studied further. Additionally, this study did not measure whether using SurvivorLink increased a survivor's knowledge and understanding of their care. Our definition of meaningful use did require the registrant to engage with the ePHR and download or upload a document or send a sharing invite; rather than simply log-in. This analysis is also limited by selection bias as only survivors seen in our survivor clinic were included; however a previous analysis found survivors must first understand the importance of and be engaged in survivor care to see value in SurvivorLink [14]. Further, these results may not be generalizable to all other pediatric survivor clinics as some institutions offer continuous care for pediatric and adult aged survivors, therefore all survivors do not need to transition care at a fixed age. Finally, this was a snapshot of how SurvivorLink was used by patients seen in our clinic in a defined period of time. The clinic list and the SurvivorLink user list were linked by first and last name and therefore it is plausible that some patients may be improperly matched or missed. However, a manual review was conducted to limit this bias. Outside of this observational period, survivors have continued to register and use SurvivorLink. Today there are 341 parents of survivor $<18$ years and 296 survivors $\geq 18$ years registered on SurvivorLink and $31 \%$ have used this ePHR in a meaningful way. Future studies will evaluate longitudinal use of SurvivorLink on clinical outcomes or dissemination strategies to increase its uptake among caregivers and young adults. 


\section{Conclusion}

SurvivorLink is an ePHR designed for the unique needs of pediatric cancer survivors. Getting patients with chronic conditions to engage and know their personal risk for late effects of cancer treatment is a critical first step in making healthy medical decisions. Importantly, personal health records, such as SurvivorLink, may serve as an important bridge when childhood cancer survivors see providers outside their medical system or transition to adult care. Enabling patients to easily grant a provider access to personalized health history information at any time can alleviate potential problems or delays with health communication. This is crucial to ensure quality, life-long health care delivery for survivors of childhood cancer and may prove critical in preventing morbidity and mortality related to gaps in communication of medical information in this high-risk population.

\section{Abbreviations}

COG LTFU: Children’s Oncology Group Long-Term Follow-Up

ePHR: electronic personal health record

SHP: Survivor Healthcare Plan

\section{Multiple Choice Questions}

Who is most likely to be a meaningful user of Cancer SurvivorLink ${ }^{\mathrm{TM}}$, an electronic personal health record (ePHR) designed for survivors of pediatric cancers?

A Parent proxies of survivors with a history of a relapse of their cancer

B Survivors closer to the completion of therapy ( $<5$ years off therapy)

C A young adult transitioning to adult care

D Survivors who were treated with radiation therapy

Answer: C

As shown in Table 1, there were no differences in who was likely to be a meaningful user among SurvivorLink registrants in terms of treatment, time since completion of therapy, or history of relapse or second malignancy. However, we did find that young adult survivors who were $\geq 18$ years old and transitioned during the observation period were 2.6 (95\%CI: 1.1, 6.1) times more likely to use SurvivorLink meaningfully as compared to those who continued to receive their survivor care in our clinic, when controlling for survivor race/ethnicity.

Which subgroup of pediatric cancer survivors is more likely to return to survivor clinic for a recommended follow-up visit?

A Survivors who are registered for SurvivorLink

B Survivors who are female

C Survivors who are meaningful users of SurvivorLink

D Survivors who have private insurance

Answer: A

When controlling for survivor race/ethnicity, history of relapse or second malignancy, and age at survivor visit, SurvivorLink registrants were more likely to return to our clinic for their annual survivor care (aOR: 2.6 (95\% CI: 1.2, 5.8); \ Table 2). There was no significant difference in follow-up clinic attendance between meaningful users and those who had only registered for SurvivorLink $(\mathrm{p}=0.46)$. As shown in $>$ Table 2, patient gender and insurance type were not associated with following-up clinic attendance.

\section{Clinical Relevance Statement}

Pediatric cancer survivors are at risk for chronic and debilitating health conditions. While survivors and their parents have expressed interest in electronic personal health records (ePHRs) to manage 
their complex medical needs, this is the first article to describe how they use an ePHR. Young adult survivors of pediatric cancer who transitioned to adult care were more likely to be meaningful users and used it twice as frequently as those who continued to receive care in a pediatric survivor clinic; while, among those who continued to receive pediatric care, being a registrant was associated with returning for an annual follow-up visit.

\section{Conflict of Interest Statement}

The authors declare they have no conflict of interest relevant to this article to disclose.

\section{Human Subjects Protections}

All procedures were performed in accordance with the ethical standards of the institution and the World Medical Association Declaration of Helsinki on Ethical Principles for Medical Research Involving Human Subjects. This study was reviewed and approved by the Children's Healthcare of Atlanta Institutional Review Board. For this type of study formal consent was not required.

\section{Contributorship Statement}

R. Williamson conceptualized and designed the study, abstracted data, conducted the formal data analysis, drafted the initial manuscript, and approved the version to be published. B. Cherven conceptualized and designed the study, interpreted the data, critically revised the manuscript, and approved the version to be published. J. Gilleland Marchak critically interpreted the results and revised the manuscript, secured the funding for the data acquisition, and approved the version to be published. P. Edwards conceptualized and designed the study, reviewed the manuscript, and approved the version to be published. M. Palgon acquired the data, reviewed the manuscript, and approved the version to be published. C. Escoffery interpreted the results, reviewed the manuscript, and approved the version to be published. L. Meacham acquired the funding, conceptualized the study, critically revised the manuscript, and approved the version to be published. A. Mertens provided supervision, acquired the funding, conceptualized and designed the study, critically revised the manuscript, and approved the version to be published. All authors agree to be accountable for all aspects of the work ensuring that questions related to the accuracy or integrity of any part of the work are appropriately investigated and resolved. 


\begin{tabular}{|c|c|c|c|c|c|c|}
\hline \multicolumn{2}{|c|}{ SURVIVOR! } & & \multicolumn{4}{|c|}{$\begin{array}{l}\text { Cancer SurvivorLink } \\
\text { Your Link to Care After Cancer }\end{array}$} \\
\hline HOME & PARENTS & SURVIVORS & PROVIDERS & FIND A SURVIV & & LOGOUT \\
\hline \multicolumn{4}{|l|}{ Survivorlunk > Parents } & \multicolumn{3}{|c|}{ Search } \\
\hline $\begin{array}{c}\text { Tooboox } \\
\text { My Sunvivor's Health } \\
\text { Record } \\
\text { Provider Directory } \\
\text { Help }\end{array}$ & & & $\begin{array}{l}\text { ORE. SHARE. } \\
\text { Learn } \\
\text { Learm about you } \\
\text { term healthare }\end{array}$ & $\begin{array}{l}\rightarrow \\
\text { Survivor } \\
\text { S) and other } \\
\text { its. }\end{array}$ & 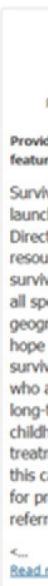 & 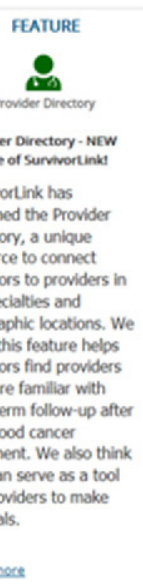 \\
\hline
\end{tabular}

Fig. 1

Cancer SurvivorLink (www.cancersurvivor link.org) User Interface 


\section{Parent Proxy (Survivors $<18$ years old)}

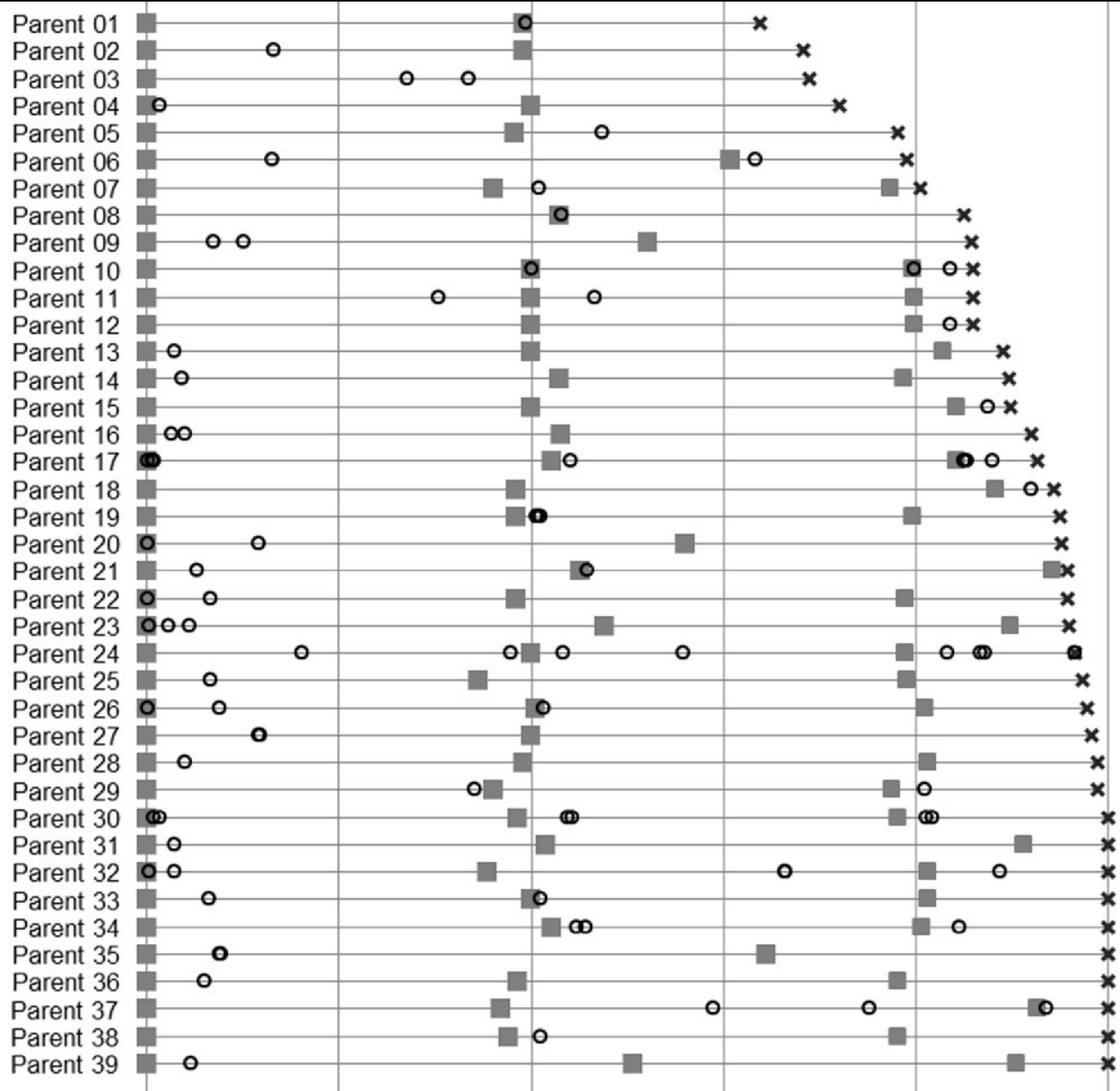

\section{Young Adult Survivors ( $\geq 18$ years old)}

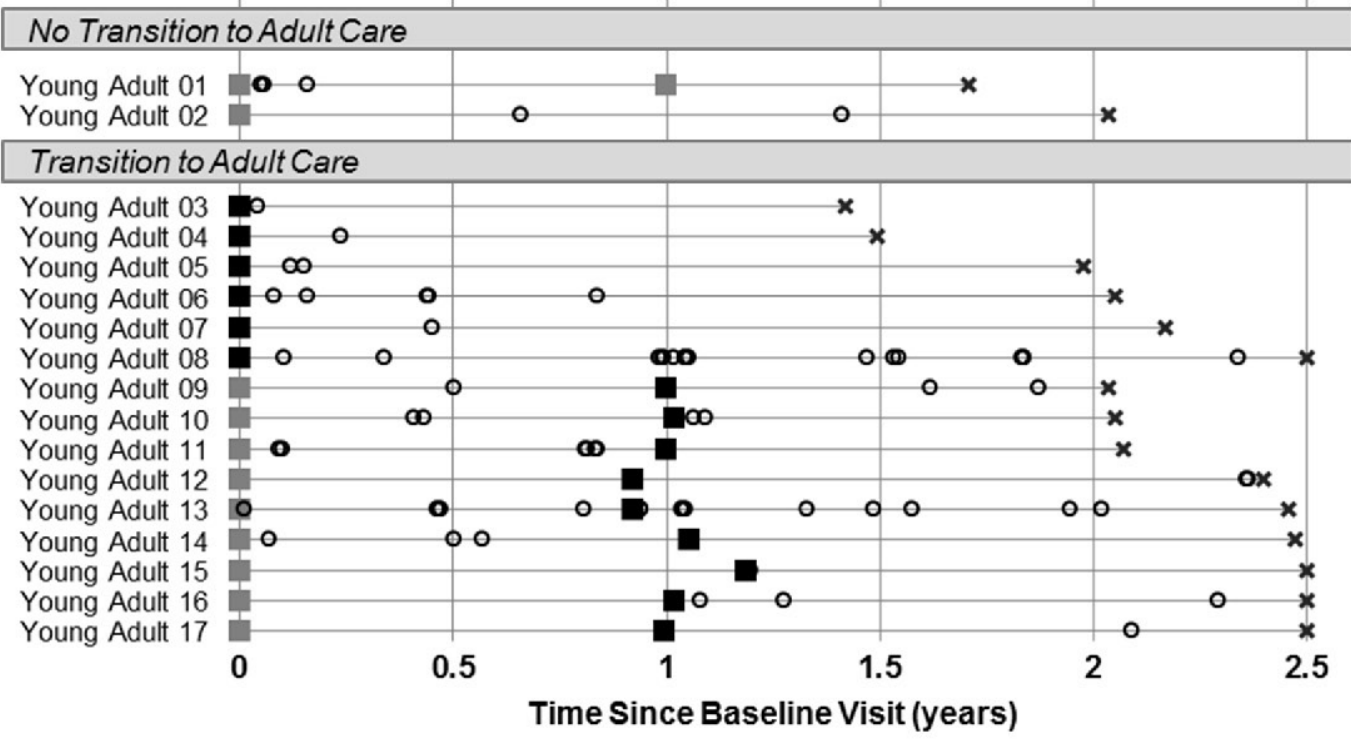

a Survivor Clinic Visit $\quad$ Transition Visit o Meaningful Event $\quad$ End of Study Follow-Up

Fig. 2 Overview of when survivors meaningfully use SurvivorLink by transition status 
Table 1 Characteristics of pediatric cancer survivors seen in survivor clinic who registered for SurvivorLink and used SurvivorLink meaningfully

\begin{tabular}{|c|c|c|c|c|c|}
\hline \multirow[t]{2}{*}{ Characteristic } & \multirow[t]{2}{*}{$\mathbf{N}$} & \multicolumn{2}{|c|}{$\begin{array}{l}\text { Among Survivors Seen in } \\
\text { Clinic - } \\
\text { SurvivorLink Registrants }\end{array}$} & \multicolumn{2}{|c|}{$\begin{array}{l}\text { Among SurvivorLink Reg } \\
\text { istrants - } \\
\text { SurvivorLink Users }{ }^{\mathrm{a}}\end{array}$} \\
\hline & & n (\%) & $p$-value ${ }^{b}$ & n (\%) & $p$-value $e^{c}$ \\
\hline Overall & 624 & \multicolumn{2}{|c|}{$148 / 624(23.7 \%)$} & \multicolumn{2}{|c|}{$56 / 148(37.8 \%)$} \\
\hline \multicolumn{6}{|l|}{ Survivor Gender } \\
\hline Male & 339 & $80(23.6 \%)$ & \multirow[t]{2}{*}{0.94} & $29(36.3 \%)$ & \multirow[t]{2}{*}{0.67} \\
\hline Female & 285 & $68(23.9 \%)$ & & $27(39.7 \%)$ & \\
\hline \multicolumn{6}{|l|}{ Survivor Race/Ethnicity } \\
\hline White, non-Hispanic & 432 & $116(26.9 \%)$ & \multirow[t]{4}{*}{0.01} & $49(42.2 \%)$ & \multirow[t]{4}{*}{0.001} \\
\hline Black, non-Hispanic & 140 & $21(15.0 \%)$ & & $1(4.8 \%)$ & \\
\hline Hispanic & 33 & $5(15.2 \%)$ & & $2(40.0 \%)$ & \\
\hline Asian & 19 & $6(31.6 \%)$ & & $4(66.7 \%)$ & \\
\hline \multicolumn{6}{|l|}{ Diagnosis } \\
\hline Leukemia & 281 & $79(28.1 \%)$ & \multirow[t]{7}{*}{0.10} & $30(38.0 \%)$ & \multirow[t]{7}{*}{0.35} \\
\hline non-Hodgkin's Lymphoma & 56 & $10(17.9 \%)$ & & $3(30.0 \%)$ & \\
\hline Hodgkin's Lymphoma & 38 & $11(29.0 \%)$ & & $7(63.6 \%)$ & \\
\hline Neuroblastoma & 67 & $14(20.9 \%)$ & & $7(50.0 \%)$ & \\
\hline Renal Tumor & 58 & $10(17.2 \%)$ & & $3(30.0 \%)$ & \\
\hline Sarcoma & 86 & $13(15.1 \%)$ & & $4(30.8 \%)$ & \\
\hline Other Malignancy & 38 & $11(29.0 \%)$ & & $2(18.2 \%)$ & \\
\hline \multicolumn{6}{|l|}{ Age at Diagnosis } \\
\hline$<5$ yrs & 375 & $90(24.0 \%)$ & \multirow[t]{4}{*}{0.74} & $29(32.2 \%)$ & \multirow[t]{4}{*}{0.24} \\
\hline $5-9.9$ yrs & 129 & $30(23.3 \%)$ & & $14(46.7 \%)$ & \\
\hline $10-14.9$ yrs & 87 & $18(20.7 \%)$ & & $7(38.9 \%)$ & \\
\hline 15-20.9 yrs & 33 & $10(30.3 \%)$ & & $6(60.0 \%)$ & \\
\hline \multicolumn{6}{|l|}{ Cancer Treatment } \\
\hline $\begin{array}{l}\text { Chemotherapy \&/or Surgery } \\
\text { Only }\end{array}$ & 381 & $86(22.6 \%)$ & \multirow[t]{3}{*}{0.64} & $28(32.6 \%)$ & \multirow[t]{3}{*}{0.25} \\
\hline Radiation (no BMT) & 151 & $40(26.5 \%)$ & & $17(42.5 \%)$ & \\
\hline BMT & 92 & $22(23.9 \%)$ & & $11(50.0 \%)$ & \\
\hline \multicolumn{6}{|l|}{ History of Relapse/SMN } \\
\hline None & 537 & $128(23.8 \%)$ & \multirow[t]{2}{*}{0.86} & $47(36.7 \%)$ & \multirow[t]{2}{*}{0.48} \\
\hline History of Relapse/SMN & 87 & $20(23.0 \%)$ & & $9(45.0 \%)$ & \\
\hline \multicolumn{6}{|c|}{ Time Since Completion of Therapy } \\
\hline$<5$ yrs & 262 & $69(26.3 \%)$ & \multirow[t]{3}{*}{0.42} & $26(37.7 \%)$ & \multirow[t]{3}{*}{0.13} \\
\hline $5-10$ yrs & 240 & $53(22.1 \%)$ & & $16(30.2 \%)$ & \\
\hline $10+$ years & 122 & $26(21.3 \%)$ & & $14(53.8 \%)$ & \\
\hline Clinic Visit Type & & & & & \\
\hline First Survivor Visit & 190 & $38(20.0 \%)$ & 0.14 & $16(42.1 \%)$ & 0.53 \\
\hline Follow-up Survivor Visit & 434 & $110(25.3 \%)$ & & $40(36.4 \%)$ & \\
\hline
\end{tabular}


Table 1 Continued

\begin{tabular}{|c|c|c|c|c|c|}
\hline \multirow[t]{2}{*}{ Characteristic } & \multirow[t]{2}{*}{$\mathbf{N}$} & \multicolumn{2}{|c|}{$\begin{array}{l}\text { Among Survivors Seen in } \\
\text { Clinic - } \\
\text { SurvivorLink Registrants }\end{array}$} & \multicolumn{2}{|c|}{$\begin{array}{l}\text { Among SurvivorLink Reg- } \\
\text { istrants - } \\
\text { SurvivorLink Users }{ }^{\mathrm{a}}\end{array}$} \\
\hline & & n (\%) & $p$-value & $n(\%)$ & $p$-value ${ }^{c}$ \\
\hline \multicolumn{6}{|l|}{ Age at Survivor Visit } \\
\hline $2-9.9$ yrs & 145 & $31(21.4 \%)$ & \multirow[t]{4}{*}{0.09} & $5(16.1 \%)$ & \multirow[t]{4}{*}{0.02} \\
\hline $10-14.9$ yrs & 222 & $64(28.8 \%)$ & & $26(40.6 \%)$ & \\
\hline $15-17.9$ yrs & 121 & $21(17.4 \%)$ & & $8(38.1 \%)$ & \\
\hline $18-21.9 \mathrm{yrs}$ & 136 & $32(23.5 \%)$ & & $17(53.1 \%)$ & \\
\hline \multicolumn{6}{|l|}{ Insurance } \\
\hline Private & 402 & $99(24.6 \%)$ & \multirow[t]{3}{*}{0.76} & $43(43.4 \%)$ & \multirow[t]{3}{*}{0.07} \\
\hline Public & 214 & $47(22.0 \%)$ & & $13(27.7 \%)$ & \\
\hline None & 8 & $2(25.0 \%)$ & & $0(0.0 \%)$ & \\
\hline \multicolumn{6}{|l|}{ Transitioned $^{d}$} \\
\hline Did not transition & 505 & $121(24.0 \%)$ & \multirow[t]{2}{*}{0.77} & $41(33.9 \%)$ & \multirow[t]{2}{*}{0.04} \\
\hline Transitioned & 119 & $27(22.7 \%)$ & & $15(55.6 \%)$ & \\
\hline \multicolumn{6}{|l|}{ Registrant Type } \\
\hline $\begin{array}{l}\text { Parent Proxy (Survivor }<18 \text { years } \\
\text { old) }\end{array}$ & 488 & $116(23.7 \%)$ & \multirow[t]{2}{*}{0.95} & $39(33.6 \%)$ & \multirow[t]{2}{*}{0.05} \\
\hline $\begin{array}{l}\text { Young Adult Survivor (Survivor } \\
\geq 18 \text { years old) }\end{array}$ & 136 & $32(23.5 \%)$ & & $17(53.1 \%)$ & \\
\hline
\end{tabular}

BMT = Bone Marrow Transplant; SMN Second Malignancy

a Uploaded or downloaded a health document to their SurvivorLink health record and/or shared the health record. ${ }^{b}$ SurvivorLink registrants compared to those who did not register

'Among SurvivorLink registrants, meaningful users compared to non-meaningful users.

${ }^{d}$ Documentation of transitioned to adult survivor clinic, out of state survivor clinic, or primary care physician during study period

Table 2 Among survivors eligible for pediatric follow-up, characteristics of survivors who returned to survivor clinic compared to those with no follow-up visit

\begin{tabular}{|l|l|l|l|l|l|}
\hline Characteristic & $\begin{array}{l}\text { Follow-up } \\
\text { Visit } \\
\text { n (\%) }\end{array}$ & $\begin{array}{l}\text { No Follow-up } \\
\text { Visit } \\
\text { n (\%) }\end{array}$ & p-value & aOR (95\% CI) & p-value \\
\hline Overall & $496(88.6 \%)$ & $64(11.4 \%)$ & & \\
\hline Survivor Gender & $270(90.0 \%)$ & $30(10.0 \%)$ & 0.25 & \\
\hline Male & $226(86.9 \%)$ & $34(13.1 \%)$ & & \\
\hline Female & $337(88.0 \%)$ & $46(12.0 \%)$ & 0.52 & $0.8(0.4,1.4)$ & 0.39 \\
\hline Survivor Race/Ethnicity & $159(89.8 \%)$ & $18(10.2 \%)$ & & Ref & \\
\hline White, non-Hispanic & & & & \\
\hline non-White & & & & \\
\hline
\end{tabular}


Table 2 Continued

\begin{tabular}{|c|c|c|c|c|c|}
\hline Characteristic & $\begin{array}{l}\text { Follow-up } \\
\text { Visit } \\
\text { n ( } \%)\end{array}$ & $\begin{array}{l}\text { No Follow-up } \\
\text { Visit } \\
\text { n (\%) }\end{array}$ & p-value & aOR $(95 \% \mathrm{CI})$ & p-value \\
\hline \multicolumn{6}{|l|}{ Age at Diagnosis } \\
\hline$<5$ yrs & $311(87.9 \%)$ & $43(12.1 \%)$ & \multirow[t]{4}{*}{0.33} & & \\
\hline $5-9.9$ yrs & $109(91.6 \%)$ & $10(8.4 \%)$ & & & \\
\hline $10-14.9$ yrs & $63(90.0 \%)$ & $7(10.0 \%)$ & & & \\
\hline $15-20.9 \mathrm{yrs}$ & $13(76.5 \%)$ & $4(23.5 \%)$ & & & \\
\hline \multicolumn{6}{|l|}{ Treatment } \\
\hline Chemotherapy \&/or Surgery Only & $298(86.6 \%)$ & $46(13.4 \%)$ & \multirow[t]{3}{*}{0.11} & & \\
\hline Radiation (no BMT) & $120(90.2 \%)$ & $13(9.8 \%)$ & & & \\
\hline BMT & $78(94.0 \%)$ & $5(6.0 \%)$ & & & \\
\hline \multicolumn{6}{|l|}{ History of Relapse/SMN } \\
\hline None & $421(87.0 \%)$ & $63(13.0 \%)$ & \multirow[t]{2}{*}{$<0.001$} & Ref & \\
\hline History of Relapse/SMN & $75(98.7 \%)$ & $1(1.3 \%)$ & & $11.9(1.6,87.9)$ & 0.01 \\
\hline \multicolumn{6}{|c|}{ Time Since Completion of Therapy } \\
\hline$<5$ yrs & $217(91.2 \%)$ & $21(8.8 \%)$ & \multirow[t]{3}{*}{0.06} & & \\
\hline $5-10$ yrs & $199(88.8 \%)$ & $25(11.2 \%)$ & & & \\
\hline $10+y r s$ & $80(81.6 \%)$ & $18(18.4 \%)$ & & & \\
\hline \multicolumn{6}{|l|}{ Clinic Visit Type } \\
\hline First Survivor Visit & $152(87.9 \%)$ & $21(12.1 \%)$ & \multirow[t]{2}{*}{0.73} & & \\
\hline Follow-up Survivor Visit & $344(88.9 \%)$ & $43(11.1 \%)$ & & & \\
\hline \multicolumn{6}{|l|}{ Age at Survivor Visit } \\
\hline $2-9.9 \mathrm{yrs}$ & $132(93.0 \%)$ & $10(7.0 \%)$ & \multirow[t]{4}{*}{0.10} & Ref & \\
\hline $10-14.9$ yrs & $192(87.3 \%)$ & $28(12.7 \%)$ & & $0.5(0.2,1.1)$ & 0.07 \\
\hline $15-17.9$ yrs & $107(89.9 \%)$ & $12(10.1 \%)$ & & $0.7(0.3,1.6)$ & 0.39 \\
\hline $18-21.9 \mathrm{yrs}$ & $65(82.3 \%)$ & $14(17.7 \%)$ & & $0.3(0.1,0.8)$ & 0.01 \\
\hline \multicolumn{6}{|l|}{ Insurance } \\
\hline Private & $308(88.0 \%)$ & $42(12.0 \%)$ & \multirow[t]{3}{*}{0.26} & & \\
\hline Public & $184(90.2 \%)$ & $20(9.8 \%)$ & & & \\
\hline None & $4(66.7 \%)$ & $2(33.3 \%)$ & & & \\
\hline \multicolumn{6}{|l|}{ SurvivorLink Use } \\
\hline Not Registered & $368(86.8 \%)$ & $56(13.2 \%)$ & \multirow[t]{2}{*}{0.02} & Ref & \\
\hline Registrant & $128(94.1 \%)$ & $8(5.9 \%)$ & & $2.6(1.2,5.8)$ & 0.02 \\
\hline
\end{tabular}

BMT = Bone Marrow Transplant; SMN Second Malignancy 


\section{References}

1. Howlader N, Noone A, Krapcho M, Garshell J, Neyman N, Altekruse S, Kosary CL, Yu M, Ruhl J, Tatalovich Z, Cho H, Mariotto A, Lewis DR, Chen HS, Feuer EJ, Cronin KA (eds). SEER Cancer Statistics Review, 1975-2010. Besthesda, MD [cited 2013 April]; Available from: http://seer.cancer.gov/ csr/1975_2010/, based on November 2012 SEER data submission, posted to the SEER web site, April 2013.

2. Phillips SM, Padgett LS, Leisenring WM, Stratton KK, Bishop K, Krull KR, Alfano CM, Gibson TM, de Moor JS, Hartigan DB, Armstrong GT, Robison LL, Rowland JH, Oeffinger KC, Mariotto AB. Survivors of childhood cancer in the United States: prevalence and burden of morbidity. Cancer Epidemiol Biomarkers Prev 2015; 24(4): 653-663.

3. Oeffinger KC, Mertens AC, Sklar CA, Kawashima T, Hudson MM, Meadows AT, Friedman DL, Marina N, Hobbie W, Kadan-Lottick NS, Schwartz CL, Leisenring W, Robison LL; Childhood Cancer Survivor Study. Chronic health conditions in adult survivors of childhood cancer. N Engl J Med 2006; 355(15): 1572-1582.

4. Hudson MM, Ness KK, Gurney JG, Mulrooney DA, Chemaitilly W, Krull KR, Green DM, Armstrong GT, Nottage KA, Jones KE, Sklar CA, Srivastava DK, Robison LL. Clinical ascertainment of health outcomes among adults treated for childhood cancer. JAMA 2013; 309(22): 2371-2381.

5. Children's Oncology Group. Long-Term Follow-Up Guidelines for Survivors of Childhood, Adolescent, and Young Adult Cancers Version 4.0. Version 4.0 ed2013.

6. Archer N, Fevrier-Thomas U, Lokker C, McKibbon KA, Straus SE. Personal health records: a scoping review. J Am Med Inform Assoc 2011; 18(4): 515-522.

7. Kaelber DC, Jha AK, Johnston D, Middleton B, Bates DW. A research agenda for personal health records (PHRs). J Am Med Inform Assoc 2008; 15(6): 729-736.

8. Kahn JS, Aulakh V, Bosworth A. What it takes: characteristics of the ideal personal health record. Health Aff (Millwood). 2009; 28(2): 369-376.

9. Council on Clinical Information T. Policy Statement--Using personal health records to improve the quality of health care for children. Pediatrics 2009; 124(1): 403-409.

10. Sharp LK, Carvalho P, Southward M, Schmidt ML, Jabine LN, Stolley MR, Gerber BS. Electronic Personal Health Records for Childhood Cancer Survivors: An Exploratory Study. J Adolesc Young Adult Oncol 2014; 3(3): 117-122.

11. Tom JO, Chen C, Zhou YY. Personal health record use and association with immunizations and well-child care visits recommendations. J Pediatr 2014; 164(1): 112-117.

12.Zhou YY, Leith WM, Li H, Tom JO. Personal health record use for children and health care utilization: propensity score-matched cohort analysisJ Am Med Inform Assoc 2015; 22(4): 748-754.

13. Byczkowski TL, Munafo JK, Britto MT. Variation in use of Internet-based patient portals by parents of children with chronic disease. Arch Pediatr Adolesc Med 2011; 165(5): 405-411.

14. Williamson R, Meacham L, Cherven B, Hassen-Schilling L, Edwards P, Palgon M, Espinoza S, Mertens A. Predictors of successful use of a web-based healthcare document storage and sharing system for pediatric cancer survivors: Cancer SurvivorLink. J Cancer Surviv 2014; 8(3): 355-363.

15. Centers for Medicare \& Medicaid Services. Electronic Health Records (EHR) Incentive Programs 2016 [cited 2016 February 12]; Available from: https://www.cms.gov/Regulations-and-Guidance/Legislation/ EHRIncentivePrograms/index.html?redirect=/EHRIncentivePrograms/50_Registration.asp\#TopOfPage.

16. Centers for Medicare \& Medicaid Services. Merit-based Incentive Payment System (MIPS) and Alternative Payment Model (APM) Incentive under the Physician Fee Schedule, and Criteria for Physician-Focused Payment Models Executive Summary [cited 13 December 2016]; Available from: https://qpp.cms.gov/docs/QPP_Executive_Summary_of_Final_Rule.pdf

17.Elliot DL, Lindemulder SJ, Goldberg L, Stadler DD, Smith J. Health promotion for adolescent childhood leukemia survivors: building on prevention science and ehealth. Pediatr Blood Cancer 2013; 60(6): 905-910.

18. Henderson TO, Friedman DL, Meadows AT. Childhood cancer survivors: transition to adult-focused riskbased care. Pediatrics 2010; 126(1): 129-136.

19. Nathan PC, Hayes-Lattin B, Sisler JJ, Hudson MM. Critical issues in transition and survivorship for adolescents and young adults with cancers. Cancer 2011; 117(10 Suppl.): 2335-2341.

20.Dontje K, Corser W, Holzman G. Understanding Patient Perceptions of the Electronic Personal Health Record. J Nurse Pract 2014; 10(10): 824-828.

21.Centers for Medicare \& Medicaid Services. Stage 2 Overview Tipsheet. 2012 [cited 2016 February 5]; Available from: https:/www.cms.gov/Regulations-and-Guidance/Legislation/EHRIncentivePrograms/ Downloads/Stage2Overview_Tipsheet.pdf.

22. Yamin CK, Emani S, Williams DH, Lipsitz SR, Karson AS, Wald JS, Bates DW. The digital divide in adoption and use of a personal health record. Arch Intern Med 2011; 171(6): 568-574. 
23.Price M, Bellwood P, Kitson N, Davies I, Weber J, Lau F. Conditions potentially sensitive to a personal health record (PHR) intervention, a systematic review. BMC Med Inform Decis Mak 2015; 15: 32.

24. Health Information Technology Resource Center (HITRC). The Value of Personal Health Records and Web Portals to Engage Consumers and Improve Quality. Robert Wood Johnson Foundation, 2012 [cited 2016 February 11]; Available from: http://www.rwjf.org/content/dam/farm/reports/issue_briefs/ 2012/rwjf400251.

25. Otte-Trojel T, de Bont A, van de Klundert J, Rundall TG. Characteristics of patient portals developed in the context of health information exchanges: early policy effects of incentives in the meaningful use program in the United States. J Med Internet Res 2014; 16(11): e258.

26. Ancker JS, Silver M, Kaushal R. Rapid growth in use of personal health records in New York, 2012-2013. J Gen Intern Med 2014; 29(6): 850-854.

27. Cooley WC. Adolescent health care transition in transition. JAMA Pediatr 2013; 167(10): 897-899.

28. Prior M, McManus M, White P, Davidson L. Measuring the "triple aim" in transition care: a systematic review. Pediatrics 2014; 134(6): e1648-e1661.

29. Griffin A, Skinner A, Thornhill J, Weinberger M. Patient Portals: Who uses them? What features do they use? And do they reduce hospital readmissions? Appl Clin Inform 2016; 7(2): 489-501.

30. Clark SJ, Costello LE, Gebremariam A, Dombkowski KJ. A national survey of parent perspectives on use of patient portals for their children's health care. Appl Clin Inform 2015; 6(1): 110-119. 